\title{
23erid tigungen.
}

Seite 42 3eile 1 v. u. I. Nov. 4, ftatt: 14.

- 44,4 v. u. l. Mittermaier, ft. Mittermetyer.

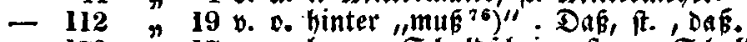

- 170. $" 17$ v. o. I. neue Sdulbideine, ft. nur Edulbid.

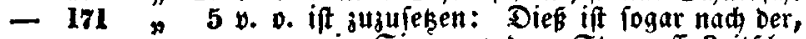
in Sinton und v. Strampf 3eitidyr. BD. I. S. 1-6 mitgetheilten $\mathfrak{A} u B$ : fübrung bie allein ridtige Infidt,

- 222 15 v. o. I. Iautet, fi. autet. reld e jedodi die Prariz nid t anerfennt.

- $444 \% 4$ v. u. I. I825, fi. 1835.

- $546 " 5$ v. o. l. Somcapitel, ft. Domcapital.

- 523 " 14 v. u. i. Domcapitel, fi. Domcapital.

- $596 \% 4$ v. u. l. zu jielenden, ff. unb jiebendem.

- $612 " 9$ v. u. l. gebumbenen privilegirten, ft. gebus. Dene privilegirte. 